\title{
Epidemiología de Listeria Monocytogenes, Salmonella Enteritidis Y Campylobacter spp., En La Cadena Productiva Avícola de Dos Regiones de Colombia.
}

\author{
Maria Elena Realpe Delgado (I), Edna Catering Rodriguez \\ Cardenas (I), Maria del Pilar Donado Godoy (II), Angela Muñoz (I), \\ Stefany Alejandra Arévalo Mayorga (II) \\ (I) INS - Instituto Nacional de Salud (Avenida calle 26 No. 51-20 - Zona 6 CAN. Bogotá- \\ Colombia), (II) COIPARS-Corpoica - Corporación Colombiana para la Investigación \\ Agropecuaria (Av. El Dorado No. 42-42. Bloque 2, Piso 1. Teusaquillo, Bogotá-Colombia)
}

\section{Resumo}

Introducción: Las enfermedades trasmitidas por alimentos (ETA) son patologías en incremento en el mundo. L. monocytogenes, S. Enteritidis y Campylobacter spp., son patógenos relacionados con ETA adquiridas al consumir alimentos de origen animal contaminados. En Colombia, la presencia de estas bacterias en todos los eslabones de la cadena avícola y sus trabajadores no se ha documentado, por lo cual, en este estudio se evaluó la epidemiología y los factores de riesgo asociados a las ETA causadas por estos patógenos en la cadena productiva avícola. Materiales y Métodos: se realizó un estudio epidemiológico observacional transversal en dos empresas integradoras avícolas (EI y EII), se recolectaron frotis de manos y muestras de materia fecal de 289 manipuladores en la EI, 241 en la EII y 424 muestras en todos los eslabones de la cadena avícola (pollitos de un día, abuelas, reproductoras, pollo de engorde, planta de beneficio y punto de venta). Se determinó fenotípica y genotípicamente la presencia de los patógenos y el personal fue encuestado para la búsqueda de factores de riesgo. Resultados: En los manipuladores, Salmonella spp. fue aislada del $3 \%$ de frotis de manos y del $4 \%$ de la materia fecal, en donde también se encontró Campylobacter spp. 0,7\% y L. monocytogenes 2\%. La presencia 
de Salmonella spp. fue mayor en los frotis de manos de la EI (OR: 4,7, $\mathrm{p}=0,005$, IC 0,58-0,697), empresa en la cual el eslabón de pollo de engorde presentó mayor frecuencia de éste patógeno tanto en manos como en materia fecal (p0,000 IC: 0,000-0,007). Campylobacter spp. y L. monocytogenes se encontraron en materia fecal de los galponeros de la granja de reproductoras (p0,001 IC: 0,00-0,070) y en manipuladores de la planta de beneficio (p 0,006 IC 0,014-0,045). La presencia de estos microorganismos en la EII no fue significativa. El análisis de los factores de riesgo en la EI, mostró que no lavarse las manos y no recibir capacitación en prácticas higiénicas y medidas de protección ( $\mathrm{p}=0,009$; $\mathrm{P}=0,02$ ) son determinantes para la presentación de Salmonella spp. en el personal. En las muestras de origen animal, la prevalencia de Salmonella spp. fue del 10\%, encontrándose en mayor proporción en granja de pollo de engorde 34\% (24/77). Campylobacter spp. fue aislado del 7\% (31) y L.monocytogenes del 0.2\% (1) de las muestras evaluadas. En el análisis comparativo de Salmonella sp. por PFGE, para los aislamientos de la cadena productiva se determinaron 5 clusters con porcentajes de coeficiente de similitud (\%CS) entre 60-100, de la Salmonella sp. recuperada de humanos, se encontraron 4 serotipos predominantes relacionados en más del 75\%. Conclusión: La presencia de estos patógenos en diversos eslabones de la cadena avícola y los trabajadores, evidencia el riesgo de contaminación del producto terminado y la necesidad de ajustar las medidas de contención y control del proceso. Se encontró que en las dos empresas el pollo de engorde es el que mayor nivel riesgo presenta.

Palavras-Chave: Cadena avicola, Listeria monocytogenes, Salmonella Enteritidis, Campylobacter spp, Factores de riesgo

Agência de Fomento: COLCIENCIAS 